\title{
El autoritarismo de derechas como sustrato psicosocial de odio
}

El autoritarismo de derechas como sustrato psicosocial de odio ${ }^{1}$

Carlos Iván Orellana*

Recibido el 27 de octubre de 2017, aceptado para su publicación el 20 de noviembre de 2017

\begin{abstract}
Resumen
Una expresión y un instigador probable de la psicología de los crímenes de odio es el llamado autoritarismo de derechas. Estas tendencias antidemocráticas, conservadoras y punitivas son identificables en $\mathrm{El}$ Salvador de hoy vinculadas a las condiciones de alta inseguridad, violencia e incertidumbre que experimenta el país. El artículo teoriza sobre el autoritarismo de derechas y ofrece los resultados de una escala original para medir el fenómeno. Los resultados principales reconfirman que las actitudes autoritarias existen en la población salvadoreña y que se ven alimentadas por aspectos como la percepción de anomia o del prejuicio hacia los delincuentes. Se concluye con algunas implicaciones y posibilidades futuras de investigación.
\end{abstract}

\section{Palabras Clave}

Autoritarismo de derechas, Psicología de crímenes de odio, Homofobia, Comunidad LGBTI, Actitudes, Violencia.

\begin{abstract}
An expression and a probable instigator of the Psychology of Hate Crimes is the so-called Right-wing authoritarianism. These undemocratic, conservative and punitive tendencies are identifiable in contemporary $\mathrm{El}$ Salvador linked to the conditions of high insecurity, violence and uncertainty that the country experiences. The article theorized about Right-wing Authoritarianism and offer some results of an original scale for measuring the phenomenon. The main results reconfirm that authoritarian attitudes exist in the Salvadoran population and that they are fed by aspects such
\end{abstract}

1. Este artículo constituye una versión modificada y actualizada del capítulo: Orellana, C.I. (2017). Proclivity to Hate: Violence, Group Targeting and Authoritarianism in El Salvador. En E. Dumbar, A. Blanco \& D. Crévecoeur-MacPhail (Eds.), The Psychology of Hate Crimes as Domestic Terrorism: U.S. and Global Issues (Vol. I) (pp.239-281). Santa Barbara, CA.: Praeger Publishers.

* Doctor en Ciencias Sociales. Investigador de la Universidad Don Bosco, ivan.orellana@udb.edu.sv 
as the perception of anomie or the prejudice towards the delinquents. It concludes with some implications and future research possibilities.

\section{Key Words}

Right-Wing Authoritarianism, Hate Crimes Psychology, Homophobia, LGBTI Community, Attitudes, Violence.

El artículo se estructura a partir de dos objetivos generales. El primero es analítico y teórico. Se reflexiona sobre lo que aquí se comprende como la proclividad para odiar en El Salvador de hoy: la existencia y manifestación de actitudes autoritarias. El "odio" del que aquí se habla remite a la categoría de crímenes de odio, es decir, cualquier acto criminal alimentado totalmente o en alguna medida por prejuicio o parcialidad (bias) hacia características identitarias reales o atribuidas de otros como género, orientación sexual, religión, membresía política, discapacidad (Cheng, 2014; Sullaway, 2017). El feminicidio, el vandalismo de sitios considerados como sagrados o el acoso a personas gay serían ejemplos de crímenes de odio. Mientras el odio en sí mismo no constituye un crimen, el crimen de odio o al menos su aprobación social, se vuelve más factible cuando existe una base prejuiciosa autoritaria como la que se identifica en buena parte de la sociedad salvadoreña contemporánea.

Será argumentado que los altos niveles de violencia, de crimen y de miedo, mediados por diversos factores particulares, producen y fortalecen representaciones sociales acerca de la existencia de víctimas y de victimarios que importan socialmente. Pero, otras víctimas -mujeres, personas del colectivo $\mathrm{LGBTI}^{2}$ o delincuentes- se verían sometidas a la desatención selectiva de la sociedad al igual que ciertas disposiciones de los ciudadanos comunes que pueden convertirlos en perpetradores probables o de facto. Esta construcción diferencial y sesgada de víctimas y de victimarios se concretaría en un espectro representacional discriminatorio que encontraría una de sus expresiones consolidadas en la manifestación de actitudes autoritarias. El autoritarismo encontraría condiciones objetivas de reproducción (violencia, prácticas sociales, leyes, etc.) y constituiría una orientación social generalizada que configuraría, entre otras cosas, un sustrato subjetivo antidemocrático, conservador y punitivo que puede llegar a constituir un posible disparador de odio para señalar (target), si no es que para atacar, a individuos miembros de ciertos grupos sociales.

Con base en los fundamentos analíticos, fenomenológicos y teóricos revisados, el segundo objetivo del escrito es empírico y persigue mostrar evidencia cuantitativa sobre la manifestación de tales disposiciones en El Salvador, las actitudes autoritarias y sus características.

2. LGBTI es el acrónimo para personas Lesbianas, Gays, Bisexuales, Transgénero e Intersexuales. No es extraño encontrar variaciones del acrónimo más largas, que connotan una misma letra con distintos significados simultáneamente o que permutan las letras del mismo. 


\section{Las cifras, las víctimas y los perpetradores que importan}

El incremento gradual de la violencia y el crimen al inicio del decenio de 1990, mostraba que el país empezaba a sufrir la particular vulnerabilidad identificada en sociedades que han finalizado conflictos civiles. Según esta tendencia, después de una guerra, las tasas de homicidio tienden a crecer con independencia de los resultados del conflicto y de la situación económica del país debido, entre otros aspectos, a la inefectividad de los sistemas judiciales y policiales y las normas propias del contexto postconflicto (Morrison, Buvinic \& Shifter, 2005). En ausencia de recursos, voluntad política, estabilidad institucional o conocimiento de causa para contrarrestar tales derivas, y con persistentes niveles de desigualdad social dinamizados por la implementación de un nuevo modelo económico neoliberal, un cuarto de siglo después, la situación de crimen y de violencia se ha convertido en una realidad totalizante que permea distintas dimensiones de la existencia nacional.

La violencia en El Salvador consumiría el 29.6\% del Producto Interno Bruto nacional (Instituto para la Economía y la Paz, 2017). Aleja la inversión económica y socava el desarrollo empresarial local debido a las extorsiones (Fundación Salvadoreña para el Desarrollo Económico y Social, [FUSADES], 2014). Las instituciones de justicia y de seguridad se ven desbordadas y desnaturalizadas en su razón de ser, lo cual hace persistir altos niveles de ineficacia y de impunidad. En la actualidad se calcula que más del $80 \%$ de delitos denunciados a la Fiscalía General de la República resultan archivados, más del $70 \%$ de los casos que ingresan al sistema judicial son sobreseídos y sólo un $15 \%$ de los procesos judiciales iniciados recibe condena penal o absolutoria (Instituto Universitario de Opinión Pública, [IUDOP], 2014). Asimismo, se calcula que más de 60,000 salvadoreños han abandonado anualmente el país en las últimas tres décadas y tanto adultos como niños y niñas encuentran en la violencia uno de los motivos fundamentales para migrar (Kennedy, 2014; Orellana, 2014; Programa de las Naciones para el Desarrollo [PNUD], 2013).

Pero son las cifras relativas a muertes violentas las que suelen copar las noticias, el estupor social y la plática cotidiana. Esto es así porque, al menos en los últimos veinticinco años, las tasas de homicidios siempre han alcanzado niveles epidémicos y porque la letalidad asociada a tales hechos los convierte en una de las inquietudes ciudadanas fundamentales. Desde el fin de la guerra (junto con la situación económica), la violencia criminal y sus facetas, constituye el problema que más preocupa a los salvadoreños (IUDOP, 2014; Santacruz, 2010). Según The Economist (2017), con una tasa de homicidios nacional de 91/100,000 habitantes y una en San Salvador de 137/100,000, El Salvador en la actualidad se situaría como el país más violento del mundo con la ciudad más peligrosa del mundo. Esto es especialmente grave si se considera que no existen conflictos armados en desarrollo o que Honduras y Guatemala, como parte del Triángulo Norte centroamericano, ostentan niveles de violencia igualmente desproporcionados. 
La mayoría de los asesinatos -un 70\% de ellos- son cometidos con armas de fuego, en áreas urbanas y destacan, por su magnitud, el asesinato de hombres adultos jóvenes. En 2015, la tasa de homicidios masculinos alcanzó las 199.6 muertes por cada 100 mil habitantes, mientras la tasa de muertes de mujeres llegó a 16.8 muertes por cada cien mil habitantes (Fundación Dr. Guillermo Manuel Ungo [FUNDAUNGO], 2016). Pero el riesgo de morir de forma violenta en el país no es exclusivo de los adultos: con una tasa de homicidios de 27 sobre cien mil habitantes, El Salvador es el país donde más niños y niñas y adolescentes mueren asesinados en el mundo y el tercer país de Latinoamérica y el Caribe donde el homicidio es la principal causa de muerte de niños (Fondo de las Naciones Unidas para la Infancia [UNICEF], 2014). La frecuencia con la que mueren o matan niños y jóvenes se explica en buena medida por el protagonismo de las pandillas en la generación de violencia. La presencia de estos grupos en las dinámicas sociales y comunitarias es de tal calado que se considera que han logrado mutar en grupos de presión política, fungir como actores de seguridad pública y atemperan a conveniencia conflictos comunitarios y domésticos en los territorios que controlan (Carballo, 2015; Hernández-Anzora, 2016; Molina, 2015). Aunque en las últimas dos décadas las pandillas se han afianzado en el imaginario social como la encarnación principal de la violencia y la inseguridad en el país, no se puede sostener que sean las únicas responsables de los homicidios pues las cifras oficiales no respaldan tal aseveración (ver IUDOP, 2014).

La gestión de un entorno violento se traduce en tendencias, números frecuentes, elementos concretos para el cálculo de los riesgos y la identificación de los peligros. Se colocan rostros a las amenazas y se fortalecen representaciones sobre la violencia. Lo que incluye la progresiva y conveniente configuración representacional que construye, visibiliza o invisibiliza ciertas víctimas y ciertos victimarios. Un entorno violento estimula la producción de interpretaciones de la gravedad de la situación, de justificaciones y de demarcaciones simbólicas y grupales que discriminarán a propios y a extraños, lo cual, en un esfuerzo siempre urgente y adaptativo, fortalece esfuerzos defensivos y la búsqueda de control sobre los acontecimientos diarios. Pero de esta forma, algunas concreciones de la violencia y del crimen, como algunas víctimas y ciertos perpetradores, reales o potenciales, terminan siendo socialmente invisibilizados. Así ocurriría en El Salvador actual con los crímenes de odio, el ataque que sufren ciertos grupos sociales (mujeres y personas LGBTI), ciertos infractores (delincuentes comunes o miembros de pandillas), y aquellos victimarios enfundados en el ropaje de supuestos ciudadanos "buenos y honrados".

Las facetas de la violencia en El Salvador son múltiples, complejas e intrincadas entre sí. Los datos revisados sólo pretenden ilustrar y resaltar que, debido a un efecto combinado de magnitud, visibilidad, preocupación social y de manejos políticos, en el país pueden identificarse órdenes representacionales superpuestos pero jerárquicos de víctimas y de victimarios. La reconstrucción constante de un dato se traduce, en última instancia, en la construcción y la consolidación de una 
representación social dominante. La violencia y su gestión cotidiana propician en el país un consenso colectivo implícito que atribuye un rostro esencialmente joven y masculino a las víctimas y a los victimarios. Estos últimos, por su parte, son vistos como "monstruos", como seres inmorales y malos cuya vida está consagrada al crimen (e.g, las pandillas). El resultado de la consolidación de este imaginario hegemónico será que ciertos números, ciertas víctimas y algunos victimarios son perceptual y discursivamente devaluados al grado de perder relevancia y existencia social. Butler (2006) sostiene que en las sociedades contemporáneas existen formas de distribución y de reconocimiento del dolor y del duelo. Mientras algunas vidas y algunas muertes encuentran resonancia social, otras, en cambio, son consideradas como vidas "que no valen la pena" y cuya pérdida es indolora. Algunas vidas y algunas muertes movilizarán la indignación social, pero otras invitarán al silencio, a la denuncia sin respuesta, a privatizar el dolor de la pérdida. La estructuración del mundo entre vidas que importan y vidas que no, de fondo, responde y consolida marcos normativos excluyentes que definen quién es humano y quién no lo es (Butler, 2006, 2010).

\section{Espectro representacional autoritario: una herramienta social subjetiva para señalar grupos sociales.}

Los altos niveles de violencia en El Salvador favorecerían la cristalización de una caracterología dual y epidérmica -visible, fotografiable- de una víctima joven masculina y buena y un victimario igualmente joven y masculino, pero malvado (Hume, 2007; Martel, 2006). Pero realidades como estas contribuirían también a la emergencia de ciertos repertorios sociales y representaciones intergrupales rígidas, deprecatorias y de corte defensivo (Bar-Tal, 2007). Se propone que tales representaciones se distribuirían en un espectro compuesto por, al menos, cuatro facetas: misoginia, homofobia, moralismo y punitividad. Las dimensiones en su conjunto constituirían un espectro representacional autoritario consonante, en sentido amplio, con una cultura de la violencia y una cultura del honor (Cruz, 1997; Nisbett \& Cohen, 1996). En sentido restringido, el espectro convergería con una ideología de desigualdad que justificaría el antagonismo grupal donde diversas formas de prejuicio llegan a funcionar como un síndrome (Zick et al., 2008). Se propone que el espectro representacional mencionado cobraría especial existencia bajo la forma de dos dimensiones derivadas del mismo con fronteras permeables y cuyos componentes podrían permutarse entre sí, a saber:

a) Dimensión misógino-homofóbica: Esta se verificaría en narrativas que usualmente provienen del sector empresarial o político. Ante la multiplicación de víctimas, y en particular ante la muerte diaria y masiva de hombres jóvenes, estas claman por la defensa de un abstracto "futuro de la nación" a través de diatribas acerca de la pérdida de productividad económica, de empuje, de provisión. Valga decir, de virilidad nacional. Después de todo, las formas de dominación masculina son efectivas en la medida en que logran ser indetectables y se presentan como 
capital simbólico, como prácticas incuestionables y cargadas de deseabilidad social (Schongut, 2012). Por otro lado, el carácter misógino de esta dimensión se sirve de la menor magnitud numérica de las muertes de mujeres comparadas con las de los hombres. No obstante, se pasa por alto que el agravamiento de la violencia dirigida hacia ellas se ha profundizado en los últimos años: en 2010, el incremento proporcional de homicidios de hombres fue de $27.84 \%$ pero el de mujeres llegó a 88.54\%. Entre 2003 y 2015, entre los engañosos decrementos propiciados por la tregua entre pandillas entre 2012 y 2014, la tasa de homicidios de mujeres habría pasado de 7.4 a 16.8 muertes de mujeres por cada 100 mil habitantes (Instituto Salvadoreño para el Desarrollo de la Mujer [ISDEMU], 2010; FUNDAUNGO, 2016; IUDOP, 2014).

Si las cifras de las muertes de mujeres se ven subestimadas, peor aún lo llevan los motivos subyacentes a tales crímenes cuando parecen responder a sesgos de género. El observatorio de violencia de género contra las mujeres de la Organización de Mujeres Salvadoreñas por la Paz (ORMUSA, 2015) sostiene que las estadísticas oficiales suelen registrar las muertes de mujeres como muertes violentas u homicidios, no como feminicidios. Pero los contextos y los móviles de muchos crímenes (i.e., ámbito doméstico, celos, abuso sexual, violencia física sexualizada) revelarían que a la base existe misoginia. Según el Consejo Centroamericano de Procuradores de Derechos Humanos (2006), el feminicidio conforma una práctica extendida en Centroamérica, pero los problemas de registro de los hechos o la dificultad para diferenciar entre un homicidio y un feminicidio impiden dimensionar e intervenir adecuadamente en el problema.

Las muertes de mujeres como las personas de colectivos LGBTI constituyen el tipo ideal de muertes que no importan en El Salvador: sucesos cuya cifra es "normal” o que, de llegar a ser conocidas, no suelen ir más allá del informe que no encuentra eco en la sociedad, la esporádica noticia marginal que describe el hecho como un asesinato más, la protesta o el pronunciamiento por parte de alguna organización de derechos humanos. Pero la situación es preocupante en los últimos años. Diversas fuentes (Mellvile, Mostaza Escallon y Palmer, 2013; Mendizábal, 2012; Procuraduría para la defensa de los Derechos Humanos [PDDH], 2014; Riaz y Butoi Varga, 2017), confirman aumentos desproporcionados de crímenes de odio hacia personas LGBTI; discriminación generalizada por parte de distintas instancias (salud, justicia, legislación, etc.); inoperancia de las instituciones de seguridad y justicia ${ }^{3}$ o violencia motivada por la identidad de género de la víctima, incluyendo el asesinato con lujo de barbarie. En general, la consideración de crímenes contra personas LGBTI o los crímenes sobre mujeres por el hecho de serlo es nula o marginal en las encuestas e informes nacionales y regionales sobre inseguridad, victimización y violencia criminal (IUDOP, 2009a; 2014; Observatorio de Seguridad Ciudadana, 2013; PNUD, 2009).

3. En 2010 se creó la Ley Especial Integral para una Vida Libre de Violencia para las Mujeres en la que se tipifica el delito de feminicidio. Otra legislación relevante contra la discriminación o la violencia contra la comunidad LGTBI y las mujeres aparece en Orellana (2017). 
El papel de la religión en el señalamiento y la discriminación que sufren a distintos niveles tanto las mujeres como las personas LGBTI en esta dimensión misóginohomofóbica debe ser resaltado. Es conocido el carácter profundamente religioso y conservador de la sociedad salvadoreña como la funcionalidad ideológica de la religión (IUDOP, 2009b; Martín-Baró, 1983, 1998). Constituiría un trasfondo cultural fuertemente arraigado con base en el cual se manifestarían mucho de estas visiones misógino-homofóbicas. Según el Pew Research Center (2014), en Latinoamérica está aumentando la adhesión a posiciones religiosas pentecostales/evangélicas. Es decir, a visiones religiosas más conservadoras y espiritualistas interesadas en “la búsqueda de una conexión más personal con Dios" y en un "mayor énfasis en la moralidad”. El Salvador no sería la excepción pues en la actualidad un 40\% de la población total se adscribe ya a denominaciones evangélicas.

Pero ¿qué implica refrendar esta identidad religiosa? Entre otras cosas, según el Pew Research Center (2014), que se cree más en sanaciones divinas, la ocurrencia de milagros y en dar mayor centralidad a la religión en la vida. Para lo que nos ocupa, la afiliación a la religión pentecostal/evangélica conlleva además un mayor rechazo a la legalización del matrimonio entre personas del mismo sexo. Otras exploraciones empíricas sobre las opiniones de evangélicos sobre los derechos de personas homosexuales en Latinoamérica (Lodola \& Corral, 2010; Marcano, 2013; Pew Research Center, 2013) han mostrado que La religión evangélica como la centralidad de la religión en la vida constituyen predictores estadísticos del rechazo al matrimonio entre personas del mismo sexo. Asimismo, que dicha denominación religiosa es la que menos se muestra a favor de derechos políticos o convivir con personas gay en la misma comunidad. Con casi la totalidad de los salvadoreños declarándose como creyentes e igualmente unánimes en contra del matrimonio entre personas del mismo sexo (IUDOP, 2009b), no extraña que el país destaque como el más homofóbico de Latinoamérica en diferentes sondeos internacionales (Facultad Latinoamericana de Ciencias Sociales [FLACSO], 2010; Pew Research Center, 2013) ${ }^{4}$.

Dimensión moralista-punitiva: Esta dimensión refrenda el cliché acrítico que estigmatiza a la juventud como violenta o como "carente de valores" (Cruz, 2002; Martel, 2006; Samayoa, 2011). Por supuesto, esto es más cierto en relación con los jóvenes de estratos obrero-marginales, sujeto social prototípico que mayoritariamente engrosa las cifras de homicidios. Asimismo, la imagen rígida del victimario joven y masculino refuerza la incapacidad de la sociedad, de los informes y de los análisis de ocasión, para representarse a la mujer como victimaria (ver UNDP, 2009). Cuando una mujer ejerce violencia, la sanción social sobre ellas resulta ser más severa que la que recae sobre un hombre por

4. El discurso de grupos y de generadores de opinión con visiones conservadoras y homofóbicas requeriría un estudio aparte. Son discursos usualmente alimentados por posiciones religiosas, pseudocientíficas y moralistas que tienden a reiterar el carácter anormal, pecaminoso, promiscuo o patológico de los miembros de la comunidad LGBTI. A pesar de la aparente inflexibilidad del discurso homofóbico, una popular cadena de cable ofrece pornografía gay a demanda. Las contradicciones del pensamiento autoritario parecen resultar coherentes con el libre mercado. 
considerarse patológica, porque se obvia el contexto de sentido de su ocurrencia (e.g., violencia de pareja) o porque rompe la expectativa cultural hegemónica sobre su rol de cuido y de entrega a los otros, noción que igualmente se ve respaldadas por creencias religiosas bastante enraizadas (Åhäll, 2012; Carey \& Torres, 2010; Lagarde y de los Ríos, 2011; Santacruz, 2017; Sjöberg, 2007). Tales sesgos se perpetuarían en la sociedad y en particular en el abordaje de las instituciones de seguridad y de justicia al enfrentar casos de violencia que involucran a la mujer (ISDEMU, 2010; Mellvile et al., 2013).

Las pandillas ocupan un lugar destacado en esta dimensión moralista-punitiva. Desde su emergencia en la escena social en los 90s, han pasado de ser una juventud necesitada de oportunidades, a constituir estructuras criminales complejas, brutales y entreveradas con el crimen organizado (Cruz, 2005; IUDOP, 2014; Santacruz y Concha-Eastman, 2001). Pero en este proceso perverso de mutación hay que reconocer el decisivo papel que ha jugado el Estado y los sucesivos gobiernos. Primero, los distintos gobiernos, han fallado por el olvido de esta juventud marginada desde el fin de la guerra. Luego, por instrumentalizar políticamente su atemorizante figura, al menos durante el inicio del presente siglo, primero con políticas represivas y después con pactos oscuros que buscaban disminuir la violencia a como diera lugar para obtener réditos políticos. Según Hume (2007), la implementación de medidas de mano dura habría debilitado una ya débil democracia y constituiría una confirmación de la pervivencia de tendencias autoritarias, ahora bajo formas de populismo punitivo ${ }^{5}$. Aparte de la excepcional experiencia fallida de "tregua" que tuvo lugar entre 2012 y 2014, el enfoque que prevalece es represivo, al punto que la situación actual se define por la remilitarización de la seguridad pública (IUDOP, 2014).

Los planes y las legislaciones de corte represivo pueden ser interpretados como formas de institucionalizar disposiciones sociales latentes y un uso populista de la punitividad. Las actitudes sociales pueden verse "capturadas" en cuerpos de ley específicos en detrimento de ciertos grupos sociales haciendo que perduren y se fortalezcan con el tiempo (Merolla y Zechmeister, 2009), dado que su funcionalidad no cesa como no lo hace la amenaza que las alimenta. Es claro que en la implementación y mantenimiento de medidas represivas, priva un enfoque reduccionista que institucionaliza prácticas basada en la estigmatización, el encierro y el aniquilamiento de jóvenes. El resultado acumulado para la subjetividad social habría sido el enraizamiento aún más profundo de tendencias punitivas como forma privilegiada para enfrentar las amenazas circundantes. La

\footnotetext{
5.Dando razón del espectro representacional descrito, la negligencia de la juventud marginada como la represión característica de las medidas implementadas a lo largo de los años han probado ser medidas que tan punitivas como cargadas de misoginia: se identifica una ausencia de perspectiva de género en las políticas implementadas (y en los estudios académicos también). Parece asumirse que en las pandillas no se integran niñas ni mujeres, y por lo tanto, no existe preocupación por la intensa victimización y la particular situación de vulnerabilidad asociada a su género que sufren al interior de estos grupos (Santacruz, 2017; Santacruz y Ranum, 2010).
} 
funcionalidad social del posicionamiento de las pandillas y los jóvenes que las integran en el imaginario social, ha sido la de personificar y darle rostro al miedo. El señalamiento esencialista de enemigos públicos y la construcción de amenazas visiblilizadas (Beck, 2006; Martel, 2006) cumple finalidades defensivas inmediatas que pueden conducir a la estigmatización, al ostracismo, al reclamo por el endurecimiento de penas o la implementación de medidas de fuerza extrema (e.g., violación de derechos humanos, ejecuciones extrajudiciales).

El señalamiento de ciertos otros como amenaza consolidaría la punitividad como valor social. Serviría para alejar la atención y la responsabilidad del resto de ciudadanos comunes que, escudados en un imaginario de superioridad moral (muchas veces nutrido de posiciones elitistas o religiosas) y sometidos de manera persistente a un medio violento y criminógeno, igualmente suelen ser responsables de la violencia que afecta al país. Así lo demuestran los llamados "crímenes de intolerancia" donde personas comunes atacan o matan a otras por nimiedades como la disputa por un parqueo. Este es el tipo de perpetrador, real o potencial, que interesa a propósito del autoritarismo en tanto proclividad para odiar: el ciudadano común que cree que la razón y la moral están de su lado, que cree justificado armarse o defenderse preventivamente, porque en un entorno inestable e inseguro cualquiera constituye un adversario y puede llegar a cometer “crímenes de la buena gente" (Del Águila, 2005, Felson, 2009). En los crímenes de odio como en actos sistemáticos de daño a otros (e.g., maltrato, abuso sexual) son las personas comunes -y hasta conocidas- las que suelen verse implicadas y no necesariamente miembros de grupos radicales o personas trastornadas (Cheng, 2014; Gerstenfeld, 2013; ISDEMU, 2010; Zimbardo, 2007).

Las dimensiones del espectro revisadas (misoginia-homofobia y moralismopunitividad), sin ser las únicas, constituirían expresiones de la gestión psicosocial que propicia el contexto violento de El Salvador contemporáneo. Las dimensiones revisadas, partes de un continuum o espectro, mutuamente condicionadas e intercambiables no serían autónomas entre sí pero tampoco neutrales. No son neutrales porque responden a intereses históricos determinados y consolidan representaciones ideológicamente cargadas que, al menos, se nutren de elitismo, de sexismo y de moralismo religioso, entre otros aspectos. Se trata, en última instancia, de expresiones fragmentadas de una estructuración psicosocial más general: las actitudes autoritarias. Al hablar de actitudes autoritarias, siguiendo la tradición académica en que este estudio se inscribe, se hace referencia al autoritarismo de derechas. Según Heitmeyer (2003), un concepto sociológico de extremismo de ala derecha implica dos aspectos generales: ideologías de desigualdad y diferentes niveles de aceptación de la violencia (también Zick et al., 2008). La construcción de la realidad propia de este tipo de posturas puede llegar a proveer las justificaciones necesarias para señalar grupos específicos y, quizá, hasta llegar a anular las inhibiciones que desencadenarían el uso de la violencia contra ellos. De ahí que en este escrito, y considerando el complejo 
contexto salvadoreño y sus niveles de violencia, la existencia de este tipo de actitudes pueda ser consideradas como un sustrato de animosidad, prejuicio y de hostilidad, una base para la proclividad para el odio.

\section{Fundamentación teórica de las actitudes autoritarias}

El autoritarismo de derechas o Right Wing Authoritarianism (RWA) de Robert "Bob" Altemeyer, se reconoce como una de las aproximaciones más aceptadas para el estudio del autoritarismo como realidad subjetiva (Roccato y Converso, 1996; Stenner, 2005). En esta teoría, el adjetivo Right Wing connota la tendencia a apoyar ciegamente a la autoridad vigente y a acatar lo que dice el orden establecido. Pero, se supone, no necesariamente sitúa a la persona en términos económicos o políticos como simpatizante de derecha (Rightwinger). La palabra right tendría un significado literal y prosaico, es decir, lo apropiado, lo correcto, pues el individuo autoritario lo es porque se somete a autoridades tradicionales (Altemeyer, 1996, 2003; 2006; Molero, 2007). Según Altemeyer (1996, 2006), el RWA se refiere a rasgos de personalidad cristalizados en una actitud que a su vez se ve condicionada por la situación. La base teórica reconocida de la teoría del RWA es el aprendizaje social. Es decir, la concepción de que el comportamiento humano se origina en circunstancias sociales donde ocurren procesos de socialización, modelaje, refuerzo y estructuración cognitiva (Altemeyer, 1996; Bandura, 1999; Molero, 2007; Stenner, 2005). La teoría en cuestión, por tanto, no concibe el autoritarismo como predisposición innata sino que como expresión concreta, socialmente configurada y aprendida de intolerancia y de punitividad.

Según Duckitt $(2001,2003)$ dos patrones de socialización temprana serían importantes para el aparecimiento del RWA. El primero opone prácticas de socialización coercitivas a prácticas permisivas (cuestión ya identificada en el estudio clásico de la personalidad autoritaria de Adorno, Frenkel-Brunswik, Levinson \& Sanford, 1967). El segundo patrón de socialización corresponde a prácticas cargadas de afecto opuestas a relaciones emocionalmente indiferentes hacia el infante. Estos patrones de socialización sugieren una hipotética cadena causal que derivaría en autoritarismo: 1) los procesos de socialización favorecen el aparecimiento de ciertas disposiciones de personalidad; 2) tales disposiciones facilitan la aceptación de ciertas visiones de mundo; 3) ambos aspectos, personalidad y visiones adoptadas, activan ciertas metas motivacionales; por último, 4) estas motivaciones se expresan en actitudes o sistemas ideológicos como el RWA. El RWA emergería a partir de la influencia especial del primer patrón de socialización descrito, el que opone prácticas punitivas contra prácticas tolerantes ${ }^{6}$. Una socialización marcada por la coerción propendería

6. El segundo patrón de socialización apuntado, el que opone afecto y desafecto y en concreto la influencia del segundo polo (el desafecto), derivaría en un resultado distinto al RWA: la Orientación de Dominancia Social (Social Dominance Orientation). Esta tendencia se refiere a la búsqueda de dominación y superioridad sobre otros (Sidanius y Pratto, 1999), no a la sumisión o la obediencia como propone el RWA. 
hacia personalidades conformistas que a su vez se ven atraídas por sociedades convencionales e intolerantes hacia las desviaciones. Si el mundo es interpretado prioritariamente como un lugar peligroso, las inclinaciones fundamentales se decantan hacia la búsqueda de control y seguridad a través de actitudes conservadoras, defensivas y cohesionadoras del endogrupo, o sea, actitudes autoritarias. Una amplia evidencia empírica da razón a Duckitt sobre el modelo propuesto (Duckitt, 2001, 2003; Duckitt y Fisher, 2003; Sibley, Wilson y Duckitt, 2007). Estamos entonces ante una "actitud ideológica" (Sibley et al., 2007) con un fuerte carácter endogrupal y de corte defensivo ante lo que se interpreta como un mundo particularmente amenazante.

Siguiendo la idea fuerza de la investigación seminal de los profesores de Berkeley (Adorno et al., 1967), y rescatando los elementos que más coherencia guardaban entre sí de la personalidad autoritaria, Altemeyer (1996, 2006) entiende el autoritarismo como la covariación de lo que denomina tres conglomerados actitudinales, a saber: a) Sumisión autoritaria (Authoritarian Submission), b) Agresión autoritaria (Authoritarian Aggression) y c) Convencionalismo (Conventionalism). Debe entenderse que se habla de una sola tendencia evaluativa o actitud -el autoritarismo right, apropiado o de derechas- pero que se estructura con lo que podríamos llamar subactitudes que corresponden con la tridimensionalidad de la actitud mayor. A continuación se ahonda en cada uno de dimensiones del RWA de Altemeyer.

a) Sumisión autoritaria (Authoritarian Submission). Es decir, la aceptación voluntaria de los dictámenes y acciones de las autoridades establecidas o consideradas como legítimas, a las que se considera se debe confianza, obediencia y respeto. Tales "valores" son considerados virtudes que deben ser inculcados en los niños y motivo de corrección si se apartan de los mismos. Esta sumisión también conlleva proteccionismo para las autoridades, pues se tiende a restringir el derecho a criticarlas: "por algo" ostentan la posición que han alcanzado y saben lo que hacen. La crítica a la autoridad es mal vista porque fragmenta y desestabiliza. El proteccionismo que reciben las autoridades puede llegar a un punto de fe ciega que justificaría incluso la violación de la ley o el encubrimiento de las acciones de dichas autoridades, pues la sumisión se produce aún si aquellas se comportan de forma deshonesta, corrupta o injusta.

Según Altemeyer (2003, 2006), de hecho, uno de los aspectos más llamativos de la sumisión es la creencia en la autoridad precisamente cuando menos argumentos existen para brindarle obediencia o respeto. Ocurre en el miembro del partido político que apoya a su líder a pesar de comprobársele la comisión de algún delito o en el creyente que no mueve un ápice su fe o su confianza en la iglesia, a pesar de la ocurrencia y el encubrimiento de casos masivos de abuso sexual infantil. Las autoridades knows best y enfrentan crisis que los “ponen a prueba”. Una autoridad tiene poder real o simbólico (e.g., legal, moral o espiritual) y puede 
tratarse de una persona, un documento (e.g., la Constitución política, la Biblia), alguna ley, un valor o una figura divina. Cualquier emblema de autoridad -una cruz, una placa, una bandera- se considera digno de respeto y por encima de aquellos que carecen de tales distintivos. La sumisión autoritaria connota un "súperpatriotismo" por defender valores tradicionales nacionales.

b) Agresión autoritaria (Authoritarian Aggression). La agresión se entiende a partir de la intencionalidad de producir un daño (Martín-Baró, 1983) y en un sentido bastante amplio pues incluiría lesiones físicas, sufrimiento psicológico, pérdida financiera, aislamiento social u otro estado nocivo provocado a otros. La agresión sería autoritaria cuando se acompaña de la creencia -aún más del hecho- de que las autoridades consideradas legítimas la aprueban o su ejercicio contribuirá a mantener esa autoridad en su posición. Puede interpretarse que se tiende a realizar lecturas de la conducta humana a la usanza del "antiguo testamento". Se aprueba el control sobre los demás por coacción así como el castigo físico en la infancia. La clemencia del sistema de justicia y las reformas legales tienden a vistas con recelo y como artilugios que incitan al criminal para que continúe delinquiendo. Por supuesto, la agresión autoritaria conlleva favorabilidad hacia la pena de muerte o el fortalecimiento de penas.

En esta dimensión cabe destacar la heterofobia, es decir, la tendencia a rechazar la diferencia, a recelar y a denigrar a quienes se desvían de la "norma" (Heitmeyer, 2003; Stenner, 2005). Por supuesto, destacan como blancos más probables de esta aversión a la alteridad los grupos no convencionales (minorías religiosas, agrupaciones políticas, personas LGBTI). La evidencia empírica existente sobre el RWA relaciona estas actitudes con una amplia gama de fenómenos intergrupales políticos, sociales e ideológicos, como los prejuicios, la intolerancia y diferentes formas de chauvinismo (Duckitt, 2003). Es importante especificar que cualquiera puede llegar a ser víctima de esta agresión. Cierta evidencia muestra, de hecho, una inclinación por la victimización de grupos sociales extremadamente vulnerables, indefensos y por tanto convencionales en sumo grado, como los niños, las niñas y las mujeres (ver Altemeyer, 2006).

c) Convencionalismo (Conventionalism). Se puede entender como una fuerte aceptación y compromiso con las normas sociales tradicionales. Conllevaría la suposición de que todos deberían seguir aquello decretado por la autoridad (Altemeyer, 2003, 2006). Como factor importante destaca la religión: se cree en "la ley" de Dios y los conflictos sociales son interpretados como faltas a la misma. El individuo convencional tiende hacia el fundamentalismo, el deseo de mantener las creencias y los servicios religiosos en sus formas tradicionales y, en general, se mostraría resistente a todo lo que sugiera cambio o reforma. La idea de que las personas por sí mismas puedan desarrollar sus propias convicciones sobre lo que es moral e inmoral se desdeña. La sexualidad fuera del matrimonio se considera un "pecado" pero, incluso al interior del matrimonio, algunos comportamientos 
pueden ser reprochados. La familia ideal sería la que responda a una configuración nuclear heterosexual, lo que tácitamente refuerza los roles tradicionales de género en los que la mujer -y los hijos- debe supeditarse al esposo, quien suele -debe- ser proveedor y "cabeza de la familia”. Esto quiere decir que las mujeres deben observar con más corrección su sexualidad, su apariencia y su "decencia"; toda trasgresión a las normas siempre será considerada más grave en la mujer que en el hombre.

El convencionalismo se identifica también en la veneración y de manda de respeto de símbolos patrios, las buenas costumbres, la tradición y el linaje. La tradición equivale a un imperativo social. Ineludiblemente, la homosexualidad es considerada "pecaminosa" y como una perversión. El convencionalismo vería las costumbres sociales como universales, como no arbitrarias ni opcionales. Con respecto a este elemento vale la pena matizar que "norma" significa aquí lo que debe hacerse y no necesariamente lo que se hace. Lo que se pregona constituye un deber ser, una apariencia acorde con las tradiciones más rancias. Por otra parte, aunque el cambio en las normas es posible, en general, se aprueban reformas que las endurezcan no que las modifiquen (Altemeyer, 1996).

La caracterización de la persona autoritaria no se agota aquí. Los estudios a lo largo de los años han evidenciado llamativas peculiaridades del pensamiento autoritario (Adorno et al., 1967; Duckitt, 2003; Scheepers, Felling y Peters, 1992; Stenner, 2005). El cotejó de la escala de medición del RWA con otras muchas escalas de medición -evaluación crítica de pensamiento, actitudes hacia la justicia social, evaluación inferencial, evaluación de evidencia, y un largo etcétera-, ha arrojado información consistente acerca de las tendencias de pensamiento de la persona autoritaria (Altemeyer, 1996, 1998, 2006). Algunas de éstas son las inferencias arbitrarias, el pensamiento contradictorio, la propensión a interpretar como más serios los problemas o el sustento de dobles estándares morales. Estas y otras tendencias de pensamiento, en conjunto, explicarían la presencia en distinto grado de aspectos como la estereotipia y el prejuicio (Duckitt, 2003; Marques, Paéz \& Abrams, 1998), la rigidez de pensamiento y el recurso a una economía de la obediencia o la creencia en la supremacía moral, en buena medida apoyada en la religión y su noción de pecado (Altemeyer, 1998, 2006). También incurrirían en malabarismos cognitivos que, en búsqueda de consistencia cognitiva, evidencian flagrantes contradicciones como aducir respeto por los mandamientos ("no matarás") o "la vida" mientras se apoya la pena de muerte o el ataque a minorías (Altemeyer, 1996; Manheim, 1983).

De esta rápida caracterización del tipo ideal autoritario, destacan dos aspectos importantes de cara al contexto salvadoreño. En primer lugar, cabe reiterar uno de los aspectos nucleares del fenómeno del autoritarismo: el papel de la amenaza. En la historia de los estudios sobre el autoritarismo sobresale como hipótesis esencial que el detonante o modulador de la personalidad o de las 
actitudes antidemocráticas es alguna forma de amenaza: el desarraigo del mundo, ansiedad existencial, una crianza coercitiva, el mundo peligroso debido a "gente mala" que amenaza la decencia y las buenas costumbres, la inseguridad debido a la violencia y el crimen, la ruptura del consenso y la uniformidad social y hasta la amenaza del terrorismo (Duckitt, 2003; Feldman y Stenner, 1997; Stenner, 2005; Sibley et al., 2007; Merolla y Zechmeister, 2009).

La amenaza percibida constituye un importante predictor de la tendencia a excluir a otros y de intolerancia. Conlleva una evaluación que achaca al exogrupo la responsabilidad por impedir que el endogrupo alcance sus metas, lo cual puede justificar ataques a los miembros del primero. La amenaza puede ser tangible o simbólica en tanto que la lectura de peligro puede originarse por el menoscabo real o atribuido de un bien material (e.g., patrimonio) o de otro más abstracto (e.g., identidad) (Canetti, Halperin, Hobfoll, Shapira \& Hirsch-Hoefler, 2009). La situación de amenaza puede interactuar con disposiciones autoritarias (personalidad) para producir actitudes autoritarias o instigarlas directamente (Cohrs, Kielman, Maes \& Moeschner, 2005; Stenner, 2005). Existe evidencia que de igual forma relaciona el RWA con la comisión de crímenes de odio, pero mediados por la posibilidad de morir, como ocurre en contextos peligrosos (Cheng, 2014; Weise, Arciszewski, Verlhiac, Pyszczynski \& Greenberg, 2012).

En segundo lugar, es importante resaltar que las tendencias de pensamiento autoritario mencionadas -inferencias arbitrarias y demás- quizá se vinculan con la recurrente presencia del factor educativo en la manifestación del autoritarismo. En general, aquellas personas con menos educación suelen obtener puntajes más altos o manifestar orientaciones autoritarias más pronunciadas. Contar con menor cantidad y peor calidad de educación podría tener implicaciones importantes: baja sofisticación mental, pobre exposición a y manejo de conocimientos, realidades y perspectivas diferentes, menor intercambio con personas "extrañas", entre otras posibilidades. Distintos estudios muestran que el bajo nivel educativo se encuentra sistemáticamente vinculado con orientaciones de corte autoritario (Buchanan, DeAngelo, Ma y Taylor, 2012; Córdova, Cruz y Zeichmeister, 2015; Cruz, 1999; Marcano, 2013; Seligson, Cruz y Córdova, 2000). A partir del trabajo de Brandt \& Crawford (2016) se puede hipotetizar que el autoritarismo identificable en países como El Salvador sería, sobre todo, aquel que replica tendencias prejuiciosas que vinculan baja habilidad cognitiva, sensibilidad a las amenazas y una respuesta conservadora (o distintiva de ala derecha) dirigida a grupos etiquetados como no convencionales (e.g., personas ateas, comunidad LGBTI). 
La exploración empírica de las actitudes autoritarias: resultados principales de la escala salvadoreña de autoritarismo de derechas (SRWA).

La exploración de la cultura política democrática o la opinión pública a lo largo de los años, más que el desarrollo de esfuerzos sistemáticos específicos, es lo que ha permitido encontrar indicios claros de actitudes autoritarias en la sociedad salvadoreña: La creencia de que los derechos humanos sirven para proteger a los delincuentes (IUDOP, 1998); el rechazo abierto a convivir con personas homosexuales o a que la mujer gane más dinero que su esposo (Cruz, 2002; IUDOP, 1999a); el anhelo de ley y orden, la pena de muerte y medidas de mano dura (Cruz, 1999); la aprobación de limpiezas sociales o el encarcelamiento de niños de la calle, así como la masiva prevalencia y alcance intergeneracional del castigo físico en la infancia como forma de crianza (IUDOP, 1999b; Speizer, Goodwin, Samandari, Kim y Clyde, 2008); el incremento de la intolerancia política que viene manifestándose al menos desde 2004 al punto que las opiniones de casi siete de cada diez salvadoreños se ubica en categorías de baja tolerancia política (Córdova et al., 2015); recientemente se encuentra que un 40\% de la población concuerda con la tortura de delincuentes para lograr información valiosa y algo más de un tercio con que se lleven a cabo ejecuciones extrajudicial de pandilleros o de delincuentes (Cruz, Aguilar \& Vorobyeva, 2017).

Tres aspectos cabe subrayar: primero, el estudio del autoritarismo suele darse a propósito de otras investigaciones, especialmente encuestas. La exploración de aspectos de la cultura política y de la calidad de la democracia salvadoreña, y las encuestas de opinión pública y de victimización por su foco en las preocupaciones ciudadanas, han servido como perspectiva -esencialmente métrica- para identificar indicios del fenómeno. Su tratamiento conceptual recurre a nociones sobre autoritarismo -en algunos casos se menciona el trabajo de Altemeyer, por ejemplo- pero no se puede decir que se ha buscado guardar real fidelidad o validar un cuerpo conceptual unificado que corresponda con claridad con tales expresión antidemocrática. Segundo, los estudios muestran que diferentes factores que remiten a la situación sociomaterial de las personas -el bajo nivel educativo o una situación económica precaria- son determinantes en la afinidad con el autoritarismo. Existe suficiente evidencia empírica, especialmente en Latinoamérica, que muestra que la preocupación por la situación económica llega a operar de forma similar a como lo hacen las amenazas como la violencia y el terrorismo para activar predisposiciones autoritarias, preferir gobiernos autoritarios, rechazar el apoyo de derechos de minorías y hasta la comisión de crímenes de odio (Buchanan et al. 2012; Latinobarómtero, 2008; Merolla y Zechmeister, 2009; Orces, 2010; Ryan y Leeson, 2011). Finalmente, sea que el autoritarismo se aborde de manera directa, indirecta o a través de indicios antidemocráticos propios de la cultura política, el lector fácilmente podrá adscribir algunos de los resultados de estas encuestas a alguna de las dimensiones del espectro representacional autoritario expuesto previamente (misoginia- 
homofobia-moralismo-punitividad). Sin importar la perspectiva del estudio de ocasión, el autoritarismo permea las opiniones de los salvadoreños entre las grietas que deja la democracia real, la subjetividad sociopolítica y sus contradicciones y un contexto que incita a la defensividad, la intolerancia y al contrataque.

\section{Aspectos metodológicos generales}

Los datos del presente estudio fueron obtenidos en 2010. Se contó con una muestra representativa de los habitantes urbanos del Área Metropolitana de San Salvador $(\mathrm{AMSS})^{7}$. La muestra total fue de 421 personas mayores de 15 años $(M=$ 39.2 años, $D E=17.2$ ), de distintos estratos sociales y condición social, con una proporción de hombres (44.2\%) y de mujeres (55.8\%) acorde con los parámetros poblacionales disponibles. La muestra fue diseñada para captar la mayor diversidad social posible en uno de los municipios del país socialmente más heterogéneos, más densamente poblados y donde, hasta ahora, se presentan altos niveles de violencia, miedo y criminalidad en el país.

Se construyó una encuesta compuesta por un total de 117 preguntas. En ella, además de la escala de autoritarismo, fueron incluidas otras preguntas y otras escalas (información sociodemográfica, evaluación de la situación del país, indicadores de inseguridad y victimización, escalas de prejuicio hacia los delincuentes, anomia, escalas de disposición o personalidad autoritaria, confianza hacia las instituciones, entre otras). La escala de autoritarismo fue dividida por dimensiones para evitar tedio, aquiescencia o cualquier forma de reactividad por parte del entrevistado. La participación voluntaria, el consentimiento informado y el anonimato fueron garantizados.

La escala SRWA ha sido identificada así -como Escala de Autoritarismo de derechas o Salvadorian Right-Wing Authoritarianism Scale- para emplear la terminología usual en el manejo de escalas, para diferenciarla de las variantes existentes de la escala RWA de Altemeyer y porque cuenta con características particulares que justifican hablar de una escala nueva y distintiva. Sus antecedentes y sus fundamentos teóricos y metodológicos pormenorizados pueden ser encontrados en Orellana (2017) y en Orellana (en prensa). La escala consta de 22 ítems y presenta una estructura de respuesta en formato Likert de cinco opciones de respuesta que oscilan entre el máximo acuerdo (4) y el máximo desacuerdo (0) con cada una de las afirmaciones presentadas. En la medida en que se obtiene un puntaje alto esto indicaría que quien contesta exhibe actitudes de corte autoritario. Un puntaje bajo tiende hacia el libertarismo. El coeficiente Alfa de Cronbach de la escala general SRWA fue de .83., lo que denota una buena consistencia interna. Un análisis factorial confirmatorio realizado a través del

7. En IUDOP (2002) se aprecian pormenores del procedimiento de muestreo seguido. Este documento expone los pormenores del muestreo y el trabajo de campo así como los resultados descriptivos del estudio de Orellana y Santacruz (2003). 
método de componentes principales y rotación varimax ratificó la existencia de los tres factores teóricos del RWA de Altemeyer (validez de constructo) y en conjunto explicaron el $40.55 \%$ de la varianza de los resultados. En la tabla 1 se exponen los ítems de la SRWA ordenados según la proporción de varianza explicada por cada factor y sus respectivos coeficientes alfa alcanzados.

Tabla 1. Ítems de la escala SRWA divididos por factores ordenados por su proporción de varianza explicada y su nivel de consistencia interna.

F1: Agresión Autoritaria (18.32\% Varianza explicada) $(a=.87)$

1-Un grupo de personas comience a matar a gente que consideran indeseable

2-Si las autoridades fallan, la gente tiene derecho de tomar la justicia por su propia cuenta

3-La única forma de sacar adelante a nuestro país es eliminar por la fuerza a los que causen problemas

4-En algunos casos, se justifica que la policía torture a los sospechosos para obtener información

5 -En su comunidad o colonia capturen a un delincuente reconocido y lo linchen entre todos

6-En algunas ocasiones, la policía debería matar a los delincuentes en lugar de intentar apresarlos

7-Se deberían eliminar a los pandilleros para acabar con los constantes pleitos entre ellos

8-Se debería de implantar la pena de muerte en el país

F2: Convencionalismo (14.13\% Varianza explicada) $(a=.72)$

1-La presencia militar en las calles es necesaria para controlar la delincuencia en el país

2-Para que una familia pueda funcionar bien debe estar compuesta por un padre, una madre e hijos/as

3-Las mujeres deben ser las encargadas de las tareas domésticas

4-La homosexualidad es una perversión

5-Los problemas que tienen las personas en el país se dan porque se han alejado de dios

6-Los desastres naturales son un castigo divino

7-Todos los problemas que están sucediendo en el mundo en la actualidad están escritos en la Biblia

8-El principal objetivo en la vida es fundar una familia

9-El hombre debe ser la cabeza de la familia

F3: Sumisión Autoritaria ( $8.10 \%$ Varianza explicada) $(a=.49)$

1 -Es mejor vivir en una sociedad ordenada, a pesar de que con ello se limiten algunas libertades

2-En lugar de derechos humanos, lo que nuestro país necesita en realidad es mucha ley y orden

3-Una buena educación escolar es aquella que enfatiza la disciplina y la obediencia de los

alumnos

4-Aquellos que critican la forma en que está organizada la sociedad son resentidos sociales inconformes

5-El amor a la nación se demuestra rechazando a aquellos que critican a sus autoridades

Nota: la instrucción general para la escala, o sus dimensiones si se presentaran por separado, sería la siguiente: "Podría decirme que tan de acuerdo o en desacuerdo se encuentra con las siguientes afirmaciones".

\section{Resultados destacados}

Los puntajes de todas las escalas incluidas en la encuesta fueron convertidos a una escala de puntajes de 0-10 para facilitar su interpretación. Los promedios obtenidos en las subescalas y en la escala general de autoritarismo, considerando que un puntaje posible de 10 puntos indicaría el mayor nivel de autoritarismo, fueron los siguientes: la escala de Sumisión autoritaria alcanzó un promedio de $5.5(D E=1.22)$, el promedio de la escala de Agresión autoritaria fue de 4.9 puntos $(\mathrm{DE}=2.9)$ y la escala de Convencionalismo obtuvo un promedio de 6.9 puntos (DE $=2.1$ ), la media más alta de las tres dimensiones que conforman las actitudes 
autoritarias. Por su lado, la escala general de autoritarismo alcanzó un promedio de 6.3 puntos (DE $=1.7)$. En la tabla 2 se aprecian promedios de la escala SRWA atendiendo a variables sociodemográficas incluidas en la encuesta.

Tabla 2. Promedios y desviaciones de la escala SRWA según variables sociodemográficas.

\begin{tabular}{|c|c|c|}
\hline & & SRWA \\
\hline & Variables & $M(D E)$ \\
\hline Todos/as & & $6.3(1.7)$ \\
\hline \multicolumn{3}{|l|}{ Sexo } \\
\hline & Masculino & $6.3(1.8)$ \\
\hline & Femenino & $6.5(1.7)$ \\
\hline \multicolumn{3}{|l|}{ Edad } \\
\hline & 15 a 17 años & $6.6(1.3)$ \\
\hline & 18 a 34 años & $6.2(1.8)$ \\
\hline & Arriba de 35 años & $6.3(1.7)$ \\
\hline \multicolumn{3}{|c|}{ Nivel educativo } \\
\hline & 0-9 años de escolaridad & $6.8(1.4)$ \\
\hline & Bachillerato & $6.2(1.7)$ \\
\hline & Técnico/Universidad & $5.7(1.9)^{*}$ \\
\hline \multicolumn{3}{|c|}{ Estrato social } \\
\hline & Bajo/Obrero-marginal & $6.5(1.9)$ \\
\hline & Medio & $6.4(1.6)$ \\
\hline & Alto/medio alto & $5.6(2.0)^{*}$ \\
\hline \multicolumn{3}{|l|}{ Religión } \\
\hline & Otra/ninguna & $6.2(2.0)$ \\
\hline & Católica & $6.2(1.8)$ \\
\hline & Evangélica & $6.5(1.5)$ \\
\hline \multicolumn{3}{|c|}{ Ocupación } \\
\hline & Trabaja o estudia & $6.1(1.7)$ \\
\hline & No trabaja ni estudia & $6.6(1.5)^{*}$ \\
\hline
\end{tabular}

Entre las variables demográficas incluidas en la tabla 2 se aprecian promedios bastante uniformes de SRWA. No obstante, análisis bivariados constatan la existencia de diferencias significativas entre las medias de las variables nivel educativo, estrato social y ocupación. Quiere decir que los promedios de actitudes autoritarias son mayores en quienes cuentan con menores niveles educativos, quienes pertenecen a estratos sociales bajos y quienes al momento de la pesquisa no se encontraban trabajando o estudiando (e.g., desempleados, dedicados a oficios del hogar). 
Con el fin de ilustrar el vínculo que existe entre el autoritarismo y la gestión de amenazas, la tabla 3 muestra correlaciones entre el SRWA y variables propias de inseguridad ciudadana. Quiere decir que las orientaciones antidemocráticas aparecen en la medida en que se percibe el agravamiento de la delincuencia, conforme se cree que las leyes existentes no logran atajarla, si ha habido exposición a consecuencias y actores violentos (i.e., muerte y pandillas) y en la medida en que se han tomado o se aspira a tomar medidas defensivas contra la situación que se considera peligrosa.

Tabla 3. Correlaciones entre la escala SRWA y variables de inseguridad ciudadana

\begin{tabular}{lllllllll}
\hline & & $(1)$ & $(2)$ & $(3)$ & $(4)$ & $(5)$ & $(6)$ & $(7)$ \\
\hline (1) SRWA & & & & & & \\
(2) Delincuencia ha empeorado & $.11^{*}$ & & & & & \\
(3) Ha tomado acciones precautorias & $.20^{* *}$ & .06 & & & & \\
(4) Tiene/gustaría tener arma de fuego & $.30^{* *}$ & -.04 & $.12^{*}$ & & & \\
(5) Pandilla son problema en barrio & $.17^{* *}$ & .09 & $.18^{* *}$ & .07 & & \\
(6) Vio persona asesinada en la calle & $.13^{* *}$ & .08 & $.32^{* *}$ & $.10^{*}$ & $.26^{* *}$ & \\
(7) Leyes contra delincuencia son muy & $.23^{* *}$ & $.15^{* *}$ & .09 & .07 & .07 & .03 \\
blandas & & & & & & & \\
\hline
\end{tabular}

${ }^{*} p<.05,{ }^{* *} p<.01$.

Finalmente, se elaboró un modelo de regresión para la escala SRWA en el que fueron incluidas diferentes variables consideradas en la encuesta administrada (variables sociodemográficas, de inseguridad ciudadana, etc.). Los resultados del análisis de regresión se muestran en la tabla 4. El perfil estadístico predictor de las actitudes autoritarias medidas a través de la SRWA responde a un modelo de siete variables: la experiencia de anomia, la disposición autoritaria, el prejuicio hacia los delincuentes, la baja escolaridad, la posesión o el deseo de contar con un arma de fuego, creer que las leyes contra el crimen son suaves y la ideología de derecha. 
Tabla 4. Modelo de regresión lineal múltiple para la escala SRWA

\begin{tabular}{lcccc}
\hline & B & Error & B & Sig. \\
\hline Escala SRWA & & & & \\
Constante & 2.996 & .617 & & .0001 \\
Anomia & .322 & .058 & .287 & .0001 \\
Disposición Autoritaria & .196 & .041 & .241 & .0001 \\
Prejuicio hacia delincuentes & .176 & .041 & .217 & .0001 \\
Baja escolaridad &. .087 & .024 & -.182 & .0001 \\
Tiene o quiere un arma de fuego & .681 & .183 & .181 & .0001 \\
Leyes contra delincuencia son muy blandas & .847 & .273 & .155 & .002 \\
Ideología de derecha & .126 & .042 & .145 & .003 \\
{$[F(7,239)=28.750, p<.0001], R^{2}=0.457$} & & & & \\
\hline
\end{tabular}

Nota: fue aplicado el Método por pasos (Stepwise).Las variables independientes el modelo han sido ordenadas a partir del peso del Coeficiente Beta Estandarizado.

De la tabla 4, primero, cabe destacar la importante proporción de varianza que logra la escala SRWA: $45 \%$ de la varianza de los resultados responde al influjo de siete factores incluidos en el modelo de la SRWA. El primer factor, la anomia, fue medida a través de un constructo creado $(\alpha=.71)$ a partir de la fusión de las conocidas escalas de Srole (1956; también Seeman, 1991) y de McClosky y Schaar (1965). La escala de anomia remite a la percepción de que el mundo y uno mismo se encuentran a la deriva, desorientados, faltos de reglas claras y de asideros normativos o relacionales confiables. Ofrece indicios de dificultades para hacer inteligible el mundo, de retraimiento social y de pesimismo.

El prejuicio hacia los delincuentes quizá constituye uno de los indicios más claros que por ahora se pueden ofrecer acerca del moralismo y la punitividad propia del espectro representacional autoritario. La escala de prejuicio construida $(\alpha=.43)$ mide prejuicio manifiesto y prejuicio sutil (Allport, 1971). Es decir, respectivamente, desprecio abierto por motivos patologizantes (locura) o biológicos (genética) o debido a una supuesta superioridad moral (valores religiosos o formas de educación). Es decir, los enunciados conllevan el supuesto implícito de que los delincuentes son considerados como individuos diferentes, defectuosos, malos, mientras que los "ciudadanos buenos y honrados" se constituyen en "otros" naturalmente mejores, con valores superiores, cuando en realidad en una sociedad violenta y donde las normas son vulneradas constantemente y de manera generalizada, tales fronteras pueden ser, además de difusas o falsas, el fruto de lecturas autocomplacientes. Finalmente, la disposición autoritaria se refiere al autoritarismo en cuanto rasgo de personalidad. Se ha registrado a partir de la aproximación de Feldman y Stenner (1997) y Stenner (2005) según la cual los valores de crianza exploran de forma no invasiva disposiciones elementales autoritarias. La disposición autoritaria se confirma en la medida en que se concuerda con los ítems de una escala $(\alpha=.58)$ cuyos ítems establecen que la crianza de niños debe responder a valores conformistas (respeto a mayores, obediencia, buenos modales) en lugar de valores libertarios (independencia, autoconfianza, curiosidad). 
En segundo lugar, el resto de factores incluidos en el modelo de regresión destacan desde un punto de vista teórico. La disposición autoritaria, la baja escolaridad y la ideología de derecha constituyen expresiones de sumisión y convencionalismo así como contar o querer un arma de fuego y creer que las leyes contra el crimen son muy blandas remiten a un perfil defensivo, punitivo y "asustado". Cabe mencionar que si del modelo se extraen las variables psicosociales de peso (anomia, inseguridad ciudadana, disposición autoritaria, etc.) emerge como factor preponderante la baja escolaridad, como ocurre en las encuestas de cultura política.

\section{Conclusión}

Dice el filósofo español, Santiago Alba, que si vuelven los "nazis" lo harán camuflados en su propia metáfora. Esto significa que tendemos a olvidar que el horror imposible y extremo del nazismo -su metáfora- fortalece una autocomplaciente incredulidad de lo que constituye su presencia fáctica contemporánea. Pero sería precisamente a través de la trivialización cotidiana o de la negación social de su existencia que "el nazismo" aparecería nuevamente frente a nuestros ojos. No se llamarán como se llamaban, no usarán los símbolos que ostentaban, no parecerán lo que parecían. A veces sí y serán vitoreados. No necesitarán pertenecer a grupos neonazis o de corte supremacista. Serán empresas multinacionales que condicionan las decisiones de los gobiernos, serán políticos con programas nacionalistas. Así lo atestigua el consenso neoliberal y su avasallamiento de soberanías nacionales, derechos y biografías, la erosión de libertades desde el 9/11 y la interminable "guerra contra el terror". El auge en Europa de la xenofobia institucionalizada en la arena política o la que emerge ahí donde existe una constante migración irregular. La escalada internacional de islamofobia aparejada al terrorismo yihadista o el peligro del espionaje encubierto y la invasión de la privacidad que exacerban y avizoran los avances de la tecnología digital. Y serán, por supuesto, personas comunes y corrientes, ciudadanos "buenos y honrados", supuestos demócratas que, escudados en la retórica de su temor, sus prejuicios, su religión o una mezcla de todas estas "razones" e "ideales" quienes harán suyas orientaciones autoritarias en medio de las devaluadas democracias o las peligrosas sociedades que habitan. En otras palabras, lo que se impone escudriñar en la actualidad en busca de autoritarismo es la vida cotidiana, la persona común y sus aritméticas psicosociales. También el normal andamiaje social, institucional y legal que permite su abierta o sutil reproducción al interior de nuestras sociedades.

A propósito de la normal configuración social en relación a la proclividad para odiar, hay que destacar el papel del Estado, de los distintos gobiernos y, en particular, de las leyes vigentes. Las leyes y medidas implementadas para contrarrestar la violencia o la discriminación contra personas LGBTI destacan por ser escasas, 
insuficientes y sobre todo, por asumir implícitamente que la legalidad que asiste a las personas heterosexuales es suficiente o que no hace falta promulgar leyes que contrarresten la discriminación en sus distintas formas. Las leyes y medidas punitivas han probado ser inútiles y sobre todo contraproducentes al empeorar la situación de violencia, y especialmente por contribuir a sofisticar el accionar de las pandillas. La ausencia, la insuficiencia o las deficiencias de las leyes y medidas existentes en El Salvador contra la discriminación, o aquellas diseñadas para combatir la violencia y la delincuencia, encontrarían mucho de su fundamento sociocultural y político en el espectro representacional autoritario revisado. Al mismo habría que agregar enormes dosis de negligencia, ignorancia e indiferencia social y política, como han comprobado con claridad las políticas de mano dura. Aun asumiendo que las leyes en el país fueran suficientes y adecuadas, debe reiterarse que en este país, confirmando el profundo carácter anómico de su realidad, lo usual y lo esperable es la trasgresión o la inaplicabilidad de las leyes existentes. Estas reflexiones confirman la existencia de disposiciones de ciudadanos comunes y corrientes que precisamente deben ser contrarrestadas con el concurso del Estado de derecho y la educación. El civismo, la tolerancia y el respeto a los derechos humanos del otro, del diferente, no ocurren automáticamente y menos en un contexto tan conservador, crédulo y necesitado de chivos expiatorios para calmar sus miedos cotidianos.

En nuestros contextos abundan más las preguntas que las respuestas. Por eso este trabajo inició con reflexiones y análisis, en una palabra, con hipótesis, con tareas por hacer. El paso siguiente debería ser profundizar y corroborar empíricamente la existencia del espectro representacional autoritario que ha sido esbozado: si éste es real, y se encontrara que las actitudes autoritarias modulan o se relacionan con sus manifestaciones concretas (misoginia, homofobia, moralismo y punitividad), se podría corroborar que el RWA realmente constituye una proclividad para odiar o lo que es lo mismo, que el odio se cristaliza en un punto de llegada posible del RWA. De inquietudes similares surgió la escala SRWA. Tanto sus características métricas, las confirmaciones teóricas que subyacen a su estructura como las relaciones teórico-empíricas que ofrece son prometedoras. Por ello convendría "subirse a hombros de gigantes" y seguir trayectorias que han permitido robustecer la tradición de estudio del autoritarismo pero ahora con realidades como la salvadoreña de trasfondo: explorar su vinculación con otros constructos como el etnocentrismo, formas varias de prejuicio, maquiavelismo, dominancia social o rasgos de personalidad (e.g., the Big Five), entre otros. Contrastes con otras escalas sobre autoritarismo también (e.g. la Escala F), lo que incluye alguna versión de la escala original RWA de Altemeyer. El mismo afán de profundización metodológica lleva a considerar que debe ser considerado el empleo de aproximaciones cualitativas o metodologías mixtas. Los análisis del discurso social sobre el que se erigen justificaciones que sostienen narrativas de odio, de corte autoritario u homofóbicas es una tarea pendiente en nuestro contexto. En El Salvador mucho, quizá todo, está por ser realizado. 
Como ha sido mostrado en este trabajo, la anomia se confirma como uno de los predictores estadísticos fundamentales del SRWA. Este puede ser un indicio importante a considerar en investigaciones que siempre han buscado en indicadores de inseguridad los disparadores principales de actitudes autoritarias, intolerantes o antidemocráticas. ¿Qué explicaría el peso superior de la anomia sobre la inseguridad ciudadana en la instigación del SRWA? Es probable que este efecto diferencial se deba a que la inseguridad remite a -o se mide como- una amenaza esencialmente personal e imaginable, y como tal, suficiente para evocar actitudes autoritarias. Pero la experiencia de anomia golpea la percepción de homogeneidad y de uniformidad cotidiana, lo que abre las puertas a lecturas de quiebra de valores, del estatus quo, la desconfianza hacia los líderes o la alienación respecto a los otros debido a la dilución de fronteras entre conocidos y desconocidos.

Todo esto no descarta la presencia de la percepción de amenazas a la vida (inseguridad y anomia correlacionan entre sí: $r=.15, p<.01$ ), sino que añade impredictibilidad e incertidumbre respecto al entorno y hacia los otros. La sumisión a otros legitimados en posiciones de poder, la punitividad y el aferramiento a visiones convencionales contrarrestarían este tipo de estados. Recordemos que, con Duckitt (2001, 2003), se parte del presupuesto de la existencia de configuraciones sociales coercitivas, conformistas, convencionales, sensibles a la diferencia y, por ello, que recrean visiones del mundo como un lugar peligroso. El mundo como un lugar peligroso puede ser un lugar violento, sí, pero también y quizá aún más de fondo, un lugar anómico. La anomia constituye una realidad objetiva y subjetiva que muy poca atención ha recibido en Latinoamérica. No sería la ausencia de leyes lo que mejor explicaría la comisión de crímenes de odio contra mujeres o personas LGBTI, sino su ineficaz aplicación o la vulneración constante de las leyes vigentes.

Si el peso explicativo de la anomia puede calificarse como sorpresivo y el del prejuicio hacia los delincuentes esperable, ¿qué se puede decir de la disposición autoritaria? Su presencia masiva podría llevar apresuradamente a concluir que existen indicios de personalidad autoritaria en la población salvadoreña: en promedio ocho de cada diez salvadoreños del AMSS se decantan por valores de crianza infantil autoritarios en lugar de valores libertarios. Aunque la personalidad autoritaria no puede ser descartada, Stenner (2005), nos ofrece la clave para resolver esta "invasión" o epidemia autoritaria. Según la autora, el autoritarismo en tanto disposición, constituye el determinante más importante de intolerancia entre más "aberrante" sea ésta en un contexto determinado. Pero donde la circunstancia y la cultura ofrecen elementos significativos de intolerancia o de actitudes autoritarias, las explicaciones psicologistas deben pasar a segundo plano. La presencia y el peso de la disposición autoritaria ofrecen indicios de la visión de mundo del salvadoreño promedio. Pero que en el modelo de regresión sea la experiencia de anomia lo que más explica el autoritarismo, debe conducir el análisis hacia la circunstancia social antes que a buscar reduccionistas e inescrutables condiciones intrapsíquicas. 


\section{Referencias}

Adorno, T. W., Frenkel-Brunswik, E., Levinson, D., \& Sanford, R. (1967). The Authoritarian Personality. New York: The Norton Library.

Åhäll, L. (2012). Motherhood, Myth and Gendered Agency in Political Violence. International Feminist Journal of Politics, 14(1), 103-120.

Allport, G. W. (1971). La naturaleza del prejuicio. Buenos Aires: EUDEBA.

Altemeyer, B. (1996). The Authoritarian Specter. Cambridge: Harvard University Press.

Altemeyer, B. (1998). The other "authoritarian personality". Advances in Experimental Social Psychology, 30, 47-92.

Altemeyer, B. (2003). What Happens When Authoritarians Inherit the Earth? A Simulation. Analyses of Social Issues and Public Policy, 3(1), 161-169.

Altemeyer, B. (2006). The Authoritarians. Recuperado de http://www. home.cc.umanitoba. ca/ altemey/

Bandura, A. (Ed.) (1999). Auto-eficacia: cómo afrontamos los cambios de la sociedad actual. Bilbao: Desclée De Brouwer.

Bar-Tal, D. (2007). Sociopsychological Foundations of Intractable Conflicts. American Behavioral Scientist, 50(11), 1430-1453.

Beck, U. (2006). La sociedad del riesgo. Barcelona: Paidós Surcos.

Brandt, M. \& Crawford, J. (2016). Answering Unresolved Questions about the Relationship between Cognitive Ability and Prejudice. Social Psychological and Personality Science, 7(8), 884-892. doi: 10.1177/1948550616660592

Buchanan, C., DeAngelo, L., Ma, R. \& Taylor, C. (2012). Mano Dura en las Américas: ¿Quién apoya a las políticas de mano dura? Perspectivas 80. Recuperado de http://www.vanderbilt.edu/lapop/insights/IO880es.pdf

Butler, J. (2006). Vida precaria. El poder del duelo y la violencia. Buenos Aires: Paidós.

Butler, J. (2010). Marcos de guerra. Las vidas lloradas. Madrid: Paidós.

Canetti, D., Halperin, E., Hobfoll, S., Shapira, S. \& Hirsch-Hoefler, S. (2009). 
Authoritarianism, perceived threat and exclusionism on the eve of the Disengagement: Evidence from Gaza. International Journal of Intercultural Relations, 33, 463-474. doi:10.1016/j.ijintrel.2008.12.007

Carey, D. jr. \& Torres, G. (2010). Precursors to Feminicide. Guatemalan Women in a Vortex of Violence. Latin American Research Review, 45 (3), 142-164.

Carballo, W. (2015). Impacto de la tregua entre pandillas en la vida cotidiana en un municipio libre de violencia: el caso de Santa Tecla. Estudios Centroamericanos (ECA), 70(741), 201-222.

Cheng, W. (2014). Hate Crimes and Its Relevant Factors. En M. Harry Pearson (Ed.). Crime: International Perspectives, Socioeconomic Factors and Psychological Implications (pp. 77-110). Hauppauge, NY: Nova Science Publishers.

Cohrs, J., Kielman, S., Maes, J. \& Moeschner, B. (2005). Effects of RightWing Authoritarianism and Threat from terrorism on Restriction of Civil Liberties. Analyses of Social Issues and Public Policy, 5(1), 263-276.

Consejo Centroamericano de Procuradores de Derechos Humanos (2006). I Informe Regional: Situación y análisis del femicidio en la región Centroamericana. Recuperado de http://www.americalatinagenera.org/ newsite/index.php/es/tematica/seguridad-y-justicia/violencia-contra-lasmujeres/1703-i-informe-regional-situacion-y-analisis-del-femicidio-en-laregion-centroamericana

Córdova, R., Cruz, J.M. \& Zeichmeister, E. (2015). Cultura política de la democracia en El Salvador y en las Américas, 2014: Gobernabilidad democrática a través de 10 años del Barómetro de las Américas. San Salvador: FUNDAUNGO \& LAPOP-Universidad de Vanderbilt.

Cruz, J. M. (1997). Los factores posibilitadores y las expresiones de la violencia en los noventa. Estudios Centroamericanos (ECA), 588, 977-992.

Cruz, J. M. (1999). El autoritarismo en la posguerra: un estudio de las actitudes de los salvadoreños. Estudios Centroamericanos (ECA), 603, 95-106.

Cruz, J.M. (2002). ¿Para qué sirve la democracia? La cultura política de los jóvenes del Área Metropolitana de San Salvador. Procesos, Cuaderno de trabajo 2001-01. 
Cruz, J.M. (2005). Los factores asociados a las pandillas juveniles en Centroamérica. Estudios Centroamericanos (ECA), 685-686, 1155-1182.

Cruz, J.M., Aguilar, J. \& Vorobyeva, Y. (2017). Legitimidad y confianza pública de la policía en El Salvador. San Salvador: KG-LACC, FIU \& IUDOP.

Del Águila, R. (2005). Políticas perfectas: Ideales, Moralidad y Juicio. En A. Blanco, R. del Águila \& J. M. Sabucedo. Madrid 11-M. Un análisis del mal y sus consecuencias (pp. 15-42). Madrid: Trotta.

Duckitt, J. (2001). A dual-process cognitive-motivational theory of ideology and prejudice. En M. P. Zanna (Ed.). Advances in Experimental Social Psychology (Vol. 33, pp. 41-113). New York: Academic Press.

Duckitt, J. (2003). Prejudice and Intergroup Hostility. En D. Sears, L. Huddy \& R. Jervis (Eds.), Oxford Handbook of Political Psychology (pp. 559-600). New York: Oxford University Press.

Duckitt, J. \& Fisher, K. (2003). The Impact of Social Threat on Worldview and Ideological Attitudes. Political Psychology, 21(1), 199-222.

Facultad Latinoamericana de Ciencias Sociales [FLACSO] (2010). Gobernabilidad y convivencia en América Latina. Estudio de opinión en Latinoamérica 2009-2010. Recuperado de http://www.flacso.org/ publicaciones/flacso-ipsos-final/.

Feldman, S. \& Stenner, K. (1997). Perceived Threat and Authoritarianism. Political Psychology, 18(4), 741-770.

Felson, R. (2009). Violence, Crime and Violent Crime. International Journal of Conflict and Violence, 3(1), 23-39.

Fondo de las Naciones Unidas para la Infancia [UNICEF] (2014). Hidden in Plain Sight. A Statistical Analysis of Violence Against Children. Recuperado de http://www.unicef.org/publications/index_74865.html

Fundación Guillermo Manuel Ungo [FUNDAUNGO] (2016). Evolución de los homicidios en El Salvador, 2009-junio de 2016. Boletín 04: Aportes al debate sobre la seguridad ciudadana. Recuperado de http://www.fundaungo.org. sv/pdf/2016/28112016_Aportes_4homicidios.pdf

Fundación Salvadoreña para el Desarrollo Económico y Social [FUSADES] (2014). Informe de coyuntura económica. Primer trimestre de 2014. Recuperado de http://www.fusades.org. 
Gerstenfeld, P. (2013). Hate Crimes. Causes, Controls and Controversies. (3a Ed.). Los Angeles, CA: Sage.

Hernández-Anzora, M. (2016). Las maras después de la tregua: discusión sobre su impacto político. Perspectivas 15, Fundación Friedrich Ebert. Recuperado de http://library.fes.de/pdf-files/bueros/fesamcentral/12977. pdf

Hume, M. (2007). Mano Dura: El Salvador responds to gangs. Development in Practice, 17(6), 739-751. doi: 10.1080/09614520701628121

Heitmeyer, W. (2003). Right-Wing Extremist Violence. En W. Heitmeyer \& J. Hagan (Eds.) International Handbook of Violence Research (Vol. 1) (pp. 399-436). Dordrecht, Boston, Londres: Kluwer Academic Publishers.

Instituto para la Economía y la Paz (2017). Global Peace Index 2017. Recuperado de http://visionofhumanity.org/indexes/global-peace-index/

Instituto Salvadoreño para el Desarrollo de la Mujer [ISDEMU] (2010). Segundo informe nacional sobre la situación de violencia contra las mujeres en El Salvador. Recuperado de http://www.isdemu.gob.sv.

Instituto Universitario de Opinión Pública [IUDOP] (1998). Encuesta de evaluación de Derechos Humanos. Informe 67. Recuperado de http://www. uca.edu.sv/publica/iudop/informes1a100/informe67.pdf

Instituto Universitario de Opinión Pública [IUDOP] (1999a). Encuesta sobre valores. Informe 80. Recuperado de http://www.uca.edu.sv/publica/iudop/ informes1a100/informe80.pdf

Instituto Universitario de Opinión Pública [IUDOP] (1999b). Normas culturales y actitudes sobre la violencia - Estudio Activa. San Salvador: Autor

Instituto Universitario de Opinión Pública [IUDOP] (2002). Encuesta sobre actitudes autoritarias en jóvenes residentes en la zona urbana del municipio de San Salvador. Informe 96. Recuperado de http://www.uca. edu.sv/publica/iudop/informes1a100/informe96.pdf

Instituto Universitario de Opinión Pública [IUDOP] (2009a). Victimización y Percepción de inseguridad en El Salvador. Informe 123. Recuperado de http://www.uca.edu.sv/publica/iudop/Web/2009/informe123.pdf Instituto Universitario de Opinión Pública [IUDOP] (2009b). Encuesta sobre 
la religión para las y los salvadoreños. Informe 122. Recuperado de http:// www.uca.edu.sv/publica/iudop/Web/2009/informe122.pdf

Instituto Universitario de Opinión Pública [IUDOP] (2014). La situación de la seguridad y de la justicia 2009-2014. Entre expectativas de cambio, mano dura militar y treguas. San Salvador: Autor.

Kennedy, E. (2014). No Childhood Here. Why Central American Children Are Fleeing Their Homes. Perspectives, July. Recuperado de http://www. immigrationpolicy.org

Lagarde y de los Ríos, M. (2011). Los cautiverios de las mujeres. Madresposas, monjas, putas, presas y locas. Madrid: horas y HORAS.

Latinobarómetro (2008) Informe Latinobarómetro 2008. Recuperado de http://www.latinobarometro.org.

Lodola, G. \& Corral, M. (2010). Apoyo al matrimonio entre personas del mismo sexo en América Latina. Perspectivas 44. Recuperado de http:// www.vanderbilt.edu/lapop/insights/I0844.esrevised.pdf

McClosky, H. \& Schaar, J. (1965). Psychological Dimensions of Anomy. American Sociological Review, 30 (1), 14-40.

Manheim, J. (1983). La política por dentro. Manual de actitudes y comportamiento político. México: Gernika.

Marcano, I. (2013). Evangelicalismo y derechos de los homosexuales en América Latina. Perspectivas 94. Recuperado de http://www.vanderbilt. edu/lapop/insights/I0894es.pdf

Marques, J. Paéz, D. \& Abrams, D. (1998). Social Identity on Intragroup Differentiation as Subjective Social Control. En S. Worchel, J. Morales, D. Páez \& J. Deschamps, Social Identity (pp. 124-141). Londres: Sage Publications.

Martel, R. (2006). Las maras salvadoreñas: nuevas formas de espanto y control social. Estudios Centroamericanos (ECA), 696, 957-979.

Martín-Baró, I. (1983). Acción e ideología. San Salvador: UCA Editores.

Martín-Baró, I. (1998). Psicología de la liberación. Madrid: Trotta.

Mellvile, G., Mostaza Escallon, A. \& Palmer, D. (2013). Human Rights Violations affecting Lesbian, Gay, Bisexual, Transgender and Intersexual 
(LGBTI) People in El Salvador. Solicitors' International Human Rights Group (SIHRG). Recuperado de http://www.sites.google.com/a/sihrg.org/letters/

Mendizábal, M. (2012). Diagnostico jurídico sobre Derechos Humanos de la Población LGBTI de El Salvador. Recuperado de http://www.comcavis.org. sv/archivos-categorizados/7.pdf?1419724986

Merolla, J. \& Zechmeister, E. (2009). Democracy at Risk. How terrorist Threats Affect the Public. Chicago \& Londres: The University of Chicago Press.

Molero, F. (2007). El estudio del prejuicio en la Psicología Social. En J. Morales, M. Moya, E. Gaviria \& I. Cuadrado. Psicología Social (3a Ed.) (pp. 591-617). Madrid: McGraw Hill.

Molina, N. (2015). Ni paz ni tregua para las mujeres en El Salvador. Estudios Centroamericanos (ECA), 70(741), 223-248.

Morrison, A., Buvinic, M. \& Shifter, M. (2005) América Violenta: Factores de riesgo, consecuencias e implicaciones para las políticas sobre la violencia social y doméstica. En H. Frühling \& J. Tulchin (Eds.), Crimen y Violencia en América Latina (pp. 117-151). Bogotá: Fondo de Cultura Económica.

Nisbett, R. \& Cohen, D. (1996). Culture of Honor. Colorado \& Reino Unido: Westview Press.

Observatorio de Seguridad Ciudadana (2013). Percepción de Inseguridad y Victimización por Crimen en El Salvador 2012. San Salvador: FUNDAUNGO, FLACSO El Salvador y UTEC.

Orces, D. (2010). Apoyo popular a la supresión de los derechos de las minorías. Perspectivas 34. Recuperado de http://www.vanderbilt.edu/ lapop/insights/I0834es.pdf

Orellana, C. I. (2014). Migración irregular de niños y de niñas: Ejercicio y búsqueda de ciudadanía desde la invisibilidad. Estudios Centroamericanos (ECA), 69(739), 345-374.

Orellana, C.I. (2017). Proclivity to Hate: Violence, Group Targeting and Authoritarianism in El Salvador. En E. Dumbar, A. Blanco \& D. CrévecoeurMacPhail (Eds.), The Psychology of Hate Crimes as Domestic Terrorism: U.S. and Global Issues (Vol. I) (pp.239-281). Santa Barbara, CA.: Praeger Publishers.

Orellana, C.I. (en prensa). Propiedades métricas de la Escala Salvadoreña de Autoritarismo de Derechas (SRWA). Revista Evaluar. 
Orellana, C. I. \& Santacruz, M. (2003). Actitudes autoritarias en jóvenes urbanos del municipio de San Salvador (Tesis de Maestría no publicada). Universidad Centroamericana “José Simeón Cañas” (UCA), El Salvador.

Organización de Mujeres Salvadoreñas por la Paz [ORMUSA] (2015). Indicadores de violencia. Feminicidios. Recuperado de http:// observatoriodeviolencia.ormusa.org/feminicidios.php

Pew Research Center (2013). The Global Divide on Homosexuality. Recuperado de http://www.pewglobal.org/2013/06/04/ the-global-divide-on-homosexuality/

Pew Research Center (2014). Religion in Latin America. Widespread Change in a Historically Catholic Region. Recuperado de http://www.pewforum. org/files/2014/11/Religion-in-Latin-America-11-12-PM-full-PDF.pdf

Procuraduría para la Defensa de los Derechos Humanos [PDDH] (2014). Posicionamiento ante los recientes homicidios contra la población LGBTI en El Salvador, del Procurador para la Defensa de los Derechos Humanos y del Coordinador Residente del Sistema de las Naciones Unidas. Recuperado de: www.pddh.gob.sv.

Programa de las Naciones Unidas para el Desarrollo [PNUD] (2009). Informe sobre desarrollo humano para América Central 2009-2010. Abrir espacios a la seguridad ciudadana y el desarrollo humano. San Salvador: Autor.

Programa de las Naciones Unidas para el Desarrollo [PNUD] (2013). Informe sobre desarrollo humano El Salvador 2013. Imaginar un nuevo país. Hacerlo posible. San Salvador: Autor.

Riaz, M. y Butoi Varga, S. (2017). Situación de derechos humanos de las personas LGBTI en El Salvador. Recuperado de http://hrbrief.org/hearings/ situacion-de-derechos-humanos-de-las-personas-lgbti-en-el-salvador/

Roccato, M. \& Converso, D. (1996) Cómo y porqué es necesario volver a estudiar el autoritarismo. Psicología Política, 13, 63-79.

Ryan, M. \& Leeson, P. (2011). Hate groups and hate crime. International Review of Law and Economics, 31(4), 256-262.

Samayoa, C. (2011). Ejecuciones extrajudiciales de jóvenes estigmatizados en Centroamérica: Estudio de situación de Guatemala, El Salvador y Honduras, 2009. Guatemala: PSJ, ICCPG y FESPAD.

Santacruz, M. (2010). Cinco años de violencia, delincuencia e inseguridad: 
El Salvador 2004-2008. Documentos de trabajo 2010-1, Abril. San Salvador: FUNDAUNGO.

Santacruz, M. (2017). On the Difficulties of Representation: Women in Gangs in Latin America. Hemisphere, 26, 34-35.

Santacruz, M. \& Concha-Eastman, A. (2001). Barrio adentro. La solidaridad violenta de las pandillas. San Salvador: IUDOP-Organización Panamericana de la Salud.

Santacruz, M. \& Ranum, E. (2010). "Segundos en el aire”: mujeres pandilleras y sus prisiones. San Salvador: IUDOP.

Scheepers, P., Felling, A. \& Peters, J. (1992). Anomie, Authoritarianism and Ethnocentrism: Update of a Classic Theme and a Empirical Test. Politics and the Individual, 2(1), 43-59.

Schongut, N. (2012). La construcción social de la masculinidad: poder, hegemonía y violencia. Psicología, Conocimiento y Sociedad, 2(2), 27-65

Seeman, M. (1991). Alienation and Anomie. En J. Robinson, P. Shaver \& L. Wrightsman (Eds.) Measures of Personality and Social Psychological Attitudes (pp. 291-372). San Diego, CA: Academic Press.

Seligson, M., Cruz, J.M. \& Córdova Macías, R. (2000). Auditoría de la democracia. El Salvador 1999. San Salvador: FUNDAUNGO, IUDOP \& Universidad de Pittsburgh.

Sibley, C., Wilson, M. \& Duckitt, J. (2007). Effects of Dangerous and Competitive Worldviews on Right-Wing Authoritarianism and Social Dominance Orientation over a Five-Month Period. Political Psychology, 28(3), 357-371.

Sidanius, J. \& Pratto, F. (1999). Social Dominance. An Intergroup Theory of Social Hierarchy and Oppression. Cambridge: Cambridge University Press.

Sjöberg, L. (2007). Agency, Militarized Feminity and Enemy Others: Observations from the War in Iraq. International Feminist Journal of Politics, 9(1), 82-101.

Speizer, I., Goodwin, M., Samandari, G., Kim, S. \& Clyde, M. (2008). Dimensions of Child Punishment in two Central American countries: Guatemala and El Salvador. Revista Panamericana de Salud Pública, 23(4), 247-256. 
Srole, L. (1956). Social Integration and Certain Corollaries: An Exploratory Study. American Sociological Review, 21(6), 709-716.

Stenner, K. (2005). The Authoritarian Dynamic. New York: Cambridge University Press.

Sullaway, M. (2017). Hate Crime, Violent Extremism, Domestic Terrorism Distinctions without Differences? En E. Dumbar, A. Blanco \& D. CrévecoeurMacPhail (Eds.), The Psychology of Hate Crimes as Domestic Terrorism: U.S. and Global Issues (Vol. I) (pp.89-121). Santa Barbara, CA.: Praeger Publishers.

The Economist (Marzo 31, 2017). The world's most dangerous cities. Recuperado de https://www.economist.com/blogs/graphicdetail/2017/03/ daily-chart-23

Weise, D., Arciszewski, T., Verlhiac, J. Pyszczynski, T. \& Greenberg, J. (2012). Terror Management and Attitudes Toward Immigrants. Differential Effects of Mortality Salience for Low and High Right-Wing Authoritarians. European Psychologist, 17(1), 63-72. doi: 10.1027/1016-9040/a000056

Zick, A; Wolf, C.; Küpper, B.; Davidov, E.; Schmidt, P. \& Heitmeyer, W. (2008). The Syndrome of Group-Focused Enmity: The Interrelation of Prejudices Tested with Multiple Cross-Sectional and Panel Data. Journal of Social Issues, 64(2), 363-383.

Zimbardo, P. (2007). The Lucifer Effect. Understanding How Good People Turn Evil. New York: Random House. 